ficing all hope of such appointments. Then, let them go! The whole of them, indefinitely multiplied, would be too dearly purchased by one mean solicitation.

We must notice, in conclusion, that in a free country it is impossible to hinder quackery. Laws too intolerant to be borne, and which would be a greater evil far than the one they were meant to prevent, would alone suffice for its suppression. This mode of cure no man would wish. But under any surveillance less absolute and stringent, quackery will arise in one form or another. We verily believe the best way to combat it is to destroy all conventional distinctions, and leave to the public to inquire, not whether this or that man is a corporation man or not? but, is he or is he not an educated, intelligent and skilful practitioner, and an horourable citizen?points, which there are other modes of ascertaining than a reference to the list of the Colleges of Physicians and Surgeons.

Another consideration remains. Because charlatanism brings dishonest wares to the market, are-we to prevent honest and intelligent, though poor industry, from finding a place there? This were to punish the innocent on account of the guilty. My meaning is, that, in order to prevent quackery, even were that possible, we are not justified in saying to any man: "We debar you from exercising the talents given you by God in the medical branch of science, unless you comply with certain expensive and cumbrous preliminaries appointed by us."

Bentinck-street, Manchester-square.

Robert Dick, M.D.

\section{THE PROCESS OF ELECTING A MEMBER OF COUNCIL.}

To the Eaitor of THE LANCET.

Sra,-Since the publication in your journal of the circular Mr. Wormald addressed to me, and the few remarks $I$ forwarded with it to your office on his startling and unexpected appeal to the sense of justice still-remaining amongst : those of his brother fellows who had not conspired to deprive him of the privileges due to his rank and charaeter, this gentleman has been elected a member of council, and this, too, by a majority so large as may fairly convince both him and the members, be they who they may; of the John.Hunter Club, that the machinations of a secret society, in the present age, can come to nothing else than downright ridicule. But, notwithstanding that a signal victory has been won, the objects of a conspiracy controverted, and a wholesome-lesson taught to those who vainly sought to restrict to themselves the pith and marrow of the elective franchise conferred by the charter, there were many circumstances attending that memorable Thursday, suggestive of grave and important consideration.

Suppose that Mr. Wormald had been a much less eligible person than he has -turned out to be-suppose there actually did exist certain very cogent objections to his taking his seat as member of council-nay, suppose even, as aptly but irreverently remarked by a fellow who had come a long distance to assist particularly in the solution of the question, whether Mr. Wormald should be fairly treated, the not-to-be-named personage himself had been opposed by the club, he would most assuredly have been elected had he taken his station in person on the lid of his own ballot-box.

Then, again, the business of the day was conducted without the slightest symptom of that cordial unity which should dis tinguish the occasion where the fellows are brought together for the especial object of electing one of themselves to preside over the welfare of the very institution whence they derive their professional status. The amenities of the place were totally disregarded. The gentlemen, one after the other; as they recorded their votes, crowded as far as possible from the president's chair up to the upper benches. The area of the theatre round about him was perfectly deserted; the fellows congregated aloof, standing, not sitting, on the upper seats, and there they waited the ten minutes required by the charter between the deposit of the last ball in the boxes and the declaration of the result by the president.

The announcement that $\mathbf{M r}$. Wormald was elected was received with marked approbation, especially where the crowd was thickest; a tone of triumph prevailed throughout, and continued to prevail amongst the fellows as they issued from the theatre, and even long after they left the doors of the College.

There is in all this, from first to last, a very lamentable subversion of the best intentions of the charter. Why a triumph? The legitimate purpose of this periodical assemhing of the fellows is; to the utmost, inconsistent with that sort of feeling; and why this array of one set of fellows against another? Let this question be forthwith put to those gentlemen who constitute the John-Hunter Club.

And who are those gentlemen who have contrived to raise a faction and a scandal out of an amicable ceremonial? They are not the members of the council. They are not the examined fellows, none of them having been favoured with an invitation to join the elub. They must therefore be a section of the junior honorary fellows, many of whom the ordeal of an examination would possibly have prevented from doing so much mischief as they have done by their ill-devised tactics. For much of what we want to know of the nature of their proceedings we may turn to the letter of their organ, J.H. C., published in a recent number of THE LAscer; the rest is furnished to hand by Mr. Wormald's circular. This J. H. C. may not unreasonably be regarded as the exponent of the principles of the club, since he has been permitted to say, without contradiction-

"The club have decided to support, and support only, Mr. Hodgson, Mr. Kiernan, and Mr. Dalrymple," and, (vide Mr. Wormald's circular, oppose Mr. Wormald. Again-" they (the club) are conscious of no impropriety in assembling any number of gentlemen, for the purpose of deciding how best to promote the interests of the college." A minor section of these young fellows, probably under thirty, (the black balls against $\mathrm{Mr}$. Wormald amounted to forty-four, self-constituting the Iohn-Hunter Club, accordingly did assemble. They discussed the merits of $\mathrm{Mr}$. Wormald; they put his worth and value to the ballot, and it was decided, by a single ball, to oppose his election.*

Now it may be conceded, that the determination, on the part of certain members of the club, to oppose Mr. Wormald had nothing necessarily unfair about it. The majority had an undoubted right to act according to their own views, and it is to be regretted, that the club. did not rest satisfied with the only fair result of the opportunity they afforded to each other of canvassing the eligibility of candidates, whose qualifications they conceived themselves best able (I don't know why) to estimate, and thus far, few would have heen inclined to dispute either their right to assemble to decide " how best to promote the interests of the college," or "utter a dissentient voice against their proceedings. The better, however, to secure their object, a law was framed which bound the minority to go with the majority, and in this way, if their numbers had not fortunately been so small, Mr. Wormald, that obnoxious fellow, would have been crushed altogether by that single black ball. The fellows at large were first-informed of this through Mr. Wormald's circular, and hence the foundation of the sadly unpropitious temper which brought so many fellows, from far distant places, to take part in the election, rather to register their determined opposition to clubs; cabals. and conspiracies in every form, than to secure $4 \mathrm{a}$ fit and proper person," according to the terms of the charter, to become a member of council for the ensuing year.

I will not proceed to enter at length into the miserable subterfuges of J.H.C., as they have already been : so thoroughly exposed in the leading number of THE LANCET, whieh contains his letter. "Publicity," so he says, "is the grand object of the club;" further, addressing himself particularly to you, he says, "a list" of the names of the members would be furnished on your application, and, false-Jesuit as he is, he is weak enough to expect to be believed, when he not only conchudes his dishonest assertions by an anonymous signature, but conceals the name of the place where any inquiry could be made.

Did it never oocur to the gentlemen of the John-Hunter $\mathrm{Club}$, that the majority and minority, for or against a candidate, are accurate representations of the degree of approbation in which he stands, on the part of his brother fellows, and that those terms bear intimate reference to a certain item in a man's career, called character? Did it never occur to them, that could they have had their own way, the result of every election would have been nothing less than a lie? In common justice, then, if there must be a club, let it be composed of all the fellows, without exception. There can be no difficulty on deciding as to the individual who is worthy of the title "fit and proper," if the simple plan proposed by Mr. George May, of Reading, be adopted; that is-let the names of the six fellows next on the list be published in the leading medical journals, for the consideration of the fellows at large throughout the kingdom, three months before the day of election; but above all, let the editors of journals forbear to publish anonymous comments. The addition of a writer's signature to his

* I beg to say, I was told that this was the-fact, on the day of election, by an ex-member of the club. 
contributions is, by many, considered as a most impolitic piece of hardihood, which is obviously so, when the communication itself contains statements which ought not to be made. Thus, W. B., or C., and J. H. C., the organ of the John-Hunter Club, will be constrained to maintain their incognito to the end of the chapter; and as to the members of the club, they may henceforward please themselves. Their brethren are placed far above them, where, in future, they will fearlessly contemplate, in perfect indifference, all their devices.-I remain, Sir, your obedient servant, Henry Savage, M.D. Lond., F.R.C.S.E.

Dorset-place, Dorset-square, July, 1849.

* * Dr. Savage will perceive that we have omitted a portion of his letter. The members of the Hunter Club were ashamed to write boldly in their own proper names-and had they not been suffered to declare their objects under fictitious signatures, the profession might have remained unaware of their plot, and the club might have seen their efforts crowned with success, instead of meeting with a signal and crushing defeat. -ED. L.

\section{THE JOHN-HUNTER CLUB.} To the Editor of The Lancet.

Sir,-Your correspondent of the John-Hunter Club, in the last week's number of your journal, states that "the great object of the club is publicity." In accordance with this avowal, would the secretary forthwith favour the profession with the names of its immaculate members? And the object of the club would be still more fully attained were he at the same time to publish the rules-at all events, the eighth. This is, in my opinion, the way to place the club "in its true colours before the profession."

I am, Sir, your obedient servant

July 4, 1849.

A FeLLOW.

\section{ELECTRICITY IN CHOLERA.} To the Editor of THE LANCET.

SIR,-In The Lancex of November 4, 1848, is published a concise account of an electrical phenomenon which I had remarked in a number of cholera cases-viz., the passing off of electricity from the body when under the worst stage of that disease, and this in a visible form; the knuckle of the hand being applied to any part of the body, streams of electricity might be seen averaging one inch and a half in length. It is necessary at this moment, (when we are again threatened with that formidable disease, although not in an epidemic form; for without an epidemical atmosphere indicated by meteorological occurrences or changes we cannot possibly have the epidemic cholera prevailing generally in any particular district, ) that some attention should be given to atmospherical electricityan element of essential use, and which appears to have been carefully investigated by M. Andraud, who, in a letter to the Academy of Sciences, details several experiments made with an electrical machine during the period when the cholera was most fatal in Paris, and likewise when it was declining in intensity. Of these experiments I had anticipated the results; for my statement above of the passing off of the electricity from the human body necessarily argues its deficiency in the air, which deficiency is supplied, in some measure, by the electricity evolved from the body.

As the body, so the atmosphere, cannot fulfil or accomplish the economical intentions of the great Creator, without its presence in proper quantity; as the body is affected, and ultimately destroyed, by its abstraction, its functions deranged, interrupted, and finally suspended, so is the vitality of the air destroyed when the electricity is deficient. It has been shown that the artificial supply of this fluid to the chylopoietic organs materially assists the recovery of patients, even in the collapse stage; and can it, after this, be stated that electricity is absorbed, (when the strength is rapidly decreasing, and not evolved as $I$ have mentioned, and this after a knowledge of its medical action? It is enough for me to know that when decomposition of many substances takes place, we have electricity evolved; for instance, in the decomposition of water by galvanic agency we have electricity evolved; in the composition of water we only require an electric spark, provided we have oxygen and hydrogen in proper atomic proportions; in the latter, it is my impression that electricity is absorbed; in the former, that it is evolved. I might have added more examples.

\section{PRIZES AT THE LONDON HOSPITAL.}

To the Editor of The LanceT.

$\mathrm{SrR}_{3}-$ - Your kindness in bringing before the medical world the grievances of students, makes me feel confident that a sketch of the injustice that we students annually experience will find a place in your journal.

A medical and surgical gold medal are annually awarded by the governors of this institution to two students. The one must be recommended by the physicians, the other by the surgeons, for their zeal and humanity towards the patients. There is no competition required, but only votes; and any stranger visiting the wards between the 1st of October and the month of May (when the prizes are distributed) could not help observing that one or two of the students are possessed of that not uncommon talent of getting into the good graces of the medical officers, nurses, and patients, by their petty officiousness: only such become the future prizemen, the rest remaining in statu quo.

I should be doing my fellow-students an injustice were $I$ to make any sarcastic remarks respecting the other prizes for which they compete, as the questions are of such a nature as really test their knowledge; and although some of them live with the teachers, yet they do not obtain from them any greater share of favour than others who live in lodgings; and were it not for the governors' prizes, there would be no need of complaining.-I remain, Sir, your obedient servant,

July, 1849.

C. c. J.

\section{THE "WALKER FUND."}

"IT were well, considering what Mr. Walker has done for science, if a representation of his circumstances were made by his professional brethren, to the Government, to obtain for him, if possible, some pension for the remainder of his life - a pension from the Government fund, which ought to be devoted to persons who, by their scientific or literary labours, have rendered services to their country. Meanwhile, it is necessary to relieve Mr. Walker's embarrassments; and in proposing that a subscription be opened for that purpose, it affords us great pleasure to be enabled to state that 'Dr. Alison, Professor of Practice of Medicine in the University of Edinburgh, Mr. Goodsir, Professor of Anatomy in the University of Edinburgh, and the Rev. W. Stevenson, of South Leith, have consented to receive contributions.' We are also glad to announce that Professors Sharpey and Grant, of University College, and Professors Todd and Bowman, of King's College, London, agree to become treasurers, and we hope their example will be followed in other parts of Great Britain, by gentlemen who will communicate with the treasurers in Edinburgh or in London." The Lancet, March 31st, 1849.

\section{Subscriptions received in London, and forwarded to the} Treasurers in Edinburgh:-

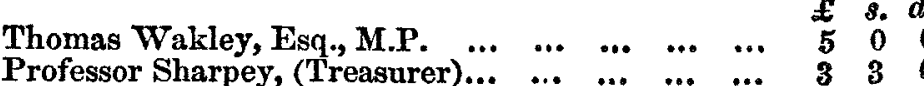
$\begin{array}{lllllllllll}\text { Professor Grant, (Treasurer) } & \ldots & \ldots & \ldots & \ldots & \ldots & \ldots & \mathbf{1} & \mathbf{1} & \mathbf{0}\end{array}$ $\begin{array}{llllllllll}\text { Professor Todd, (Treasurer) } & \ldots & \ldots & \ldots & \ldots & \ldots & \ldots & \ldots & 1 & 1 \\ \end{array}$

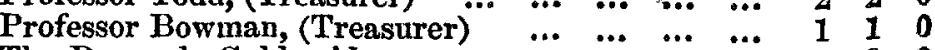

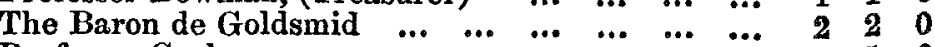

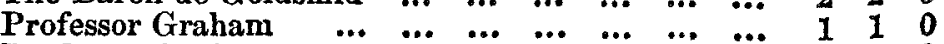

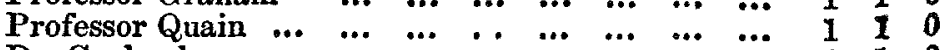

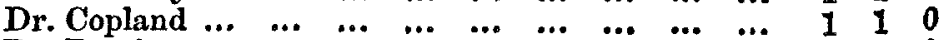
$\begin{array}{llllllllllllll}\text { Dr. Pereira } & \ldots & \ldots & \ldots & \ldots & \ldots & \ldots & \ldots & \ldots & \ldots & \ldots & \ldots & 1 & 1 \\ \end{array}$

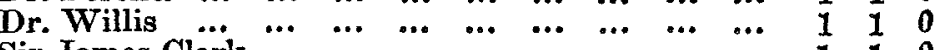
Sir James Clark ...

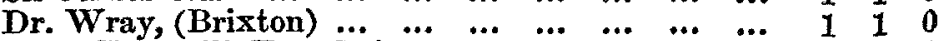
$\begin{array}{lllllllll}\text { John Churchill, Esq., Princes-street } & \ldots & \ldots & \ldots & \ldots & & 1 & 1 & 0\end{array}$ The Sub.Editor of The LanceT... Joseph Henry Green, Esq....

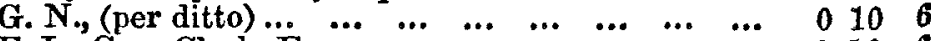
F. Le Gros Clark, Esq. $\quad \ldots \begin{array}{cccccccc} & \ldots & \ldots & \ldots & \ldots & \ldots & \ldots & \\ \end{array}$

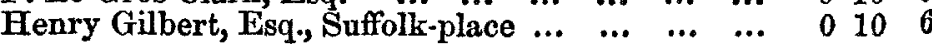

\section{THE MEDICAL PROFESSION-PAYMENT FOR} SERVICES RENDERED.

To the Editor of THE LANCET.

Sin,-I am practising my profession in a populous town re. mote from London.

I am constrained, by college regulations, from vending medicines; yet, when my prescriptions are taken to the resident chemists and druggists, I rarely find them correctly 